\title{
Pruebas serológicas para \\ COVID-19 ¿realmente ayudan? \\ A propósito de dos casos
}

\section{Do serological tests for COVID-19 really help? About two cases}

\author{
Luis Ángel Rodríguez-Chávez' \\ https://orcid.org/0000-000 I-7704-2530
}

\author{
Christian Alberto Vargas-Machuca Carranza ${ }^{2}$ \\ https://orcid.org/0000-0002-2756-9155
}

Rodríguez-Chávez L, Vargas-Machuca Carranza C. Pruebas serológicas para COVID-19 ¿realmente ayudan? A propósito de dos casos. Rev Soc Peru Med Interna. 2021;34(I): 28-30.

https://doi.org/10.36393/spmi.v34i1.581

\begin{abstract}
RESUMEN
La pandemia de la COVID-I 9 ha golpeado fuertemente a nuestro país.Actualmente, vemos como se han popularizado las pruebas serológicas y estas vienen siendo usadas no solo para el tamizaje en atención temprana sino también en el diagnóstico de la enfermedad. La máxima preocupación que se tiene es si en realidad estas pruebas podrían ser de utilidad en la detección del paciente infectado en su periodo de contagio ya que ello tiene un especial interés para la salud pública. Al respecto, se presentan dos casos, de los muchos que existen en la actualidad, y se discute sobre el tema.
\end{abstract}

Palabras claves: COVID-19, pruebas serológicas COVID-19, prueba rápida COVID-19, diagnóstico.

\section{ABSTRACT}

The COVID-19 epidemic has hit our country hard. Currently, we see how serological tests have become popular and they have been used not only for screening in early care but also in the diagnosis of the disease. The main concern that we have is whether in fact these tests could be useful in detecting the infected patient in their period of contagion, since this is of special interest for public health. In this regard, two cases, of the many ones that exist today, are presented and a discussion on the subject is made.

Keywords: COVID - 19, COVID-19 serological tests, COVID rapid test-19, diagnosis.

Médico internista. Servicio de medicina interna, Hospital de Alta Complejidad Virgen de la Puerta, Trujillo. Universidad Privada Antenor Orrego, Trujillo, Perú.

2 Residente de medicina interna. Hospital de Alta ComplejidadVirgen de la Puerta. Universidad Privada Antenor Orrego, Trujillo, Perú.

\section{INTRODUCCIÓN}

La pandemia de la COVID-19 tiene actualmente un impacto considerable no solo en la salud pública sino también en la economía de los países, en especial de los países en vías de desarrollo.

Dentro de los protocolos de prevención y tratamiento se ha optado por la realización de pruebas serológicas (pruebas rápidas) a los trabajadores asintomáticos cada 15 días y a los sintomáticos al momento de manifestar síntomas.

Al respecto de lo antes mencionado, debemos hacer hincapié en que las pruebas serológicas no tendrían validez para detectar al paciente ya sea sintomático o asintomático dentro del periodo de contagio y por lo tanto no tendrían utilidad para tomar decisiones de aislamiento; así mismo, tampoco servirían para diagnosticar a un paciente sintomático, sobre todo en los primeros días de enfermedad.

Se presentan dos casos representativos, de los muchos que vemos en la práctica diaria, en donde se evidencia que la 
estrategia de usar pruebas serológicas (pruebas rápidas) no es la mejor opción.

\section{PRESENTACIÓN DE LOS CASOS}

\section{CASO 1}

Paciente mujer de 48 años de edad, sin comorbilidades, de profesión enfermera que acude a un establecimiento de salud por presentar malestar general, dolor de garganta y fiebre. Es evaluada y le refieren que se trata de "resfrío común", siendo dada de alta con paracetamol. Dos días después se agrega anosmia y disgeusia por lo que acude nuevamente al hospital donde le realizan la prueba rápida con resultado IgM e IgG negativos, por lo que es dada de alta con paracetamol y sin indicación de aislamiento domiciliario, así la paciente continuó laborando en su hospital normalmente.

Todo el proceso caracterizado por dolor de garganta malestar general y fiebre intermitente duró aproximadamente una semana. A la semana de la primera prueba rápida, le realizan un control obteniendo igualmente el resultado IgM e IgG negativos, por lo que, ante la ausencia de síntomas, no se le realizó más estudios.

Luego de 10 días (20 días después del inicio de síntomas), la paciente se realiza de manera particular un dosaje de anticuerpos, encontrando $\operatorname{IgM} 0,641$ (negativo) e $\operatorname{IgG} 3,46$ (positivo). Con dicho resultado regresa a su hospital donde le realizan nuevamente la prueba rápida con resultado $\operatorname{IgM}$ negativo e IgG positivo por lo que le indican 14 días de aislamiento domiciliario.

\section{CASO 2}

Paciente mujer de 42 años de edad, sin comorbilidades, de profesión médico, como parte de sus controles le realizan prueba rápida cada 15 días obteniendo 8 pruebas consecutivas con IgM e IgG negativas.

En la siguiente prueba, el resultado es IgM negativo e IgG positivo; sin embargo, la paciente en ningún momento presentó síntomas, por lo que decide hacerse una prueba cuantitativa obteniendo IgM 0,3 (negativo) e IgG 4,021 (positivo). Ante ello le indican 14 días de aislamiento domiciliario.

\section{DISCUSIÓN}

El periodo de contagio de la COVID-19 va desde tres días antes hasta 14 días después del inicio de los síntomas. ${ }^{1}$ Así mismo, debemos recordar que la sensibilidad es de $30 \%$ en la primera, $78 \%$ en la segunda y $96 \%$ en la tercera semana de enfermedad. ${ }^{2,3}$ Además, el comportamiento de la carga viral, y por ende del periodo de contagio, es similar en los pacientes asintomáticos y sintomáticos. ${ }^{1,4}$ Ver Figura 1.

En pacientes asintomáticos, la prueba se realiza cada 15 días, por lo que es muy poco probable que se logre captar

Días

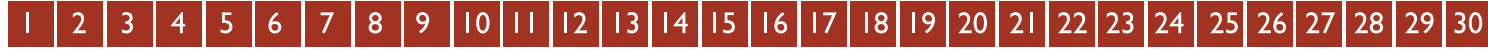

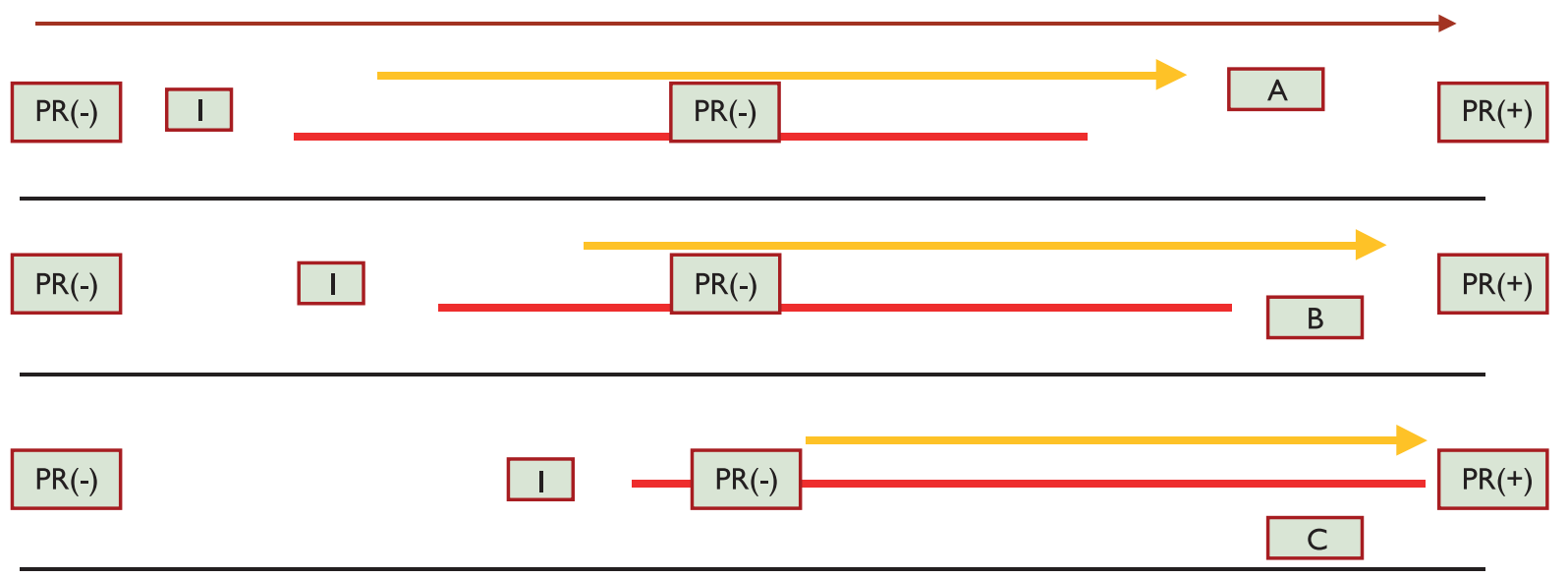

Figura I. Representación esquemática de los tres escenarios posibles de tamizaje (asintomáticos) y diagnóstico (sintomáticos) con el uso de pruebas serológicas (pruebas rápidas). PR (-): prueba rápida negativa, PR (+): prueba rápida positiva, l: momento de la infección; flecha ámbar: periodo sintomático; $y$, raya roja: periodo de contagio.

Si el paciente se infecta posterior a su primera prueba rápida negativa, la prueba rápida siguiente será dentro de la primera semana de enfermedad por lo que la sensibilidad de dicha prueba será sólo de 30 \%, y lo más probable es que resulte negativa. Recién para la siguiente prueba rápida, donde ya tendrá de 2 a 3 semanas de enfermedad, la prueba rápida es probable que resulte positiva. Es notar que el periodo de contagio de la enfermedad fue durante prueba rápida negativa. 
al paciente dentro de su periodo de contagio; y, de ahí que vemos que la mayoría de resultados son IgG positivo por lo que ya el periodo de contagio ha pasado y el aislamiento no tendrá impacto en la salud pública.

En pacientes sintomáticos, las pruebas rápidas solo tienen $30 \%$ de sensibilidad. ${ }^{2,3}$ Por lo que la siguiente frase, muy escuchada, "Tengo síntomas, pero no es COVID-19 ya que la prueba rápida salió negativa" es falsa.

En tal sentido, se ha establecido claramente que una prueba rápida negativa en la primera semana no descarta la enfermedad ya que el diagnóstico es principalmente clínico, epidemiológico y en oportunidades radiológico (tomografía). En la segunda semana de enfermedad la sensibilidad sube a $60-70 \% .^{2,3}$ Sin embargo, aún persiste por debajo de la sensibilidad considerada como buena para una prueba diagnóstica $(80 \%) .{ }^{5}$ Esto recién se logra en la tercera semana, momento en el cual el periodo de contagio está en descenso y/o el paciente ya presenta las complicaciones propias de la enfermedad.

Una alternativa a las pruebas rápidas para el diagnóstico precoz de COVID-19 en pacientes sintomáticos es el comportamiento en el tiempo del dosaje cuantitativo de anticuerpos; es decir, si se observa la primera parte de la curva (dos medidas separadas 3 a 5 días) un aumento de la cantidad de anticuerpos (aunque incluso estén dentro del rango considerado negativo) sumado al cuadro clínico apoyaría enormemente el diagnóstico de COVID-19 y nos sería de utilidad para tomar las medidas de tratamiento y prevención.

Como vemos, en ambos casos recibieron la indicación de aislamiento domiciliario recién cuando la prueba rápida mostraba el patrón IgM negativo e IgG positivo, momento en el cual la carga viral está ya en fase de defervescencia y el riesgo de contagio es mínimo o nulo; en cambio, durante su periodo de máximo contagio, ambos continuaron laborando normalmente.
En conclusión, las pruebas serológicas, también llamadas pruebas rápidas, no tienen un buen impacto en el control de la enfermedad (tratamiento y/o prevención) pues cuando ya muestran positividad el periodo de contagio prácticamente ya ha pasado. El diagnóstico en pacientes sintomáticos debe ser con la clínica asociada, idealmente, con una prueba molecular, y en algunos casos al contacto epidemiológico o estudio tomográfico. La única utilidad que tendrían las pruebas serológicas sería en cuantificar el número de casos; $\mathrm{y}$, fines de prevalencia, también su valor es relativo por cuanto habría que considerar la proporción de falsos negativos y falsos positivos.

\section{REFERENCIAS BIBLIOGRAFICAS}

I. Lee S, Kim T, Lee E, Lee C, Kim H, Rhee H, et al. Clinical course and molecular viral shedding among asymptomatic and symptomatic patients with SARS-CoV-2 infection in a community treatment center in the Republic of Korea. JAMA Intern Med [Internet]. 6 de agosto de 2020 [citado 8 de septiembre de 2020]. URL disponible en: https://jamanetwork.com/journals/ jamainternalmedicine/fullarticle/2769235

2. Interpreting diagnostic tests for SARS-CoV-2 | Infectious Diseases | JAMA | [Internet]. [citado 8 de septiembre de 2020]. URL disponible en: https://jamanetwork.com/journals/jama/fullarticle/276583

3. New Cochrane review assesses how accurate antibody tests are for detecting COVID-19 [Internet]. [citado 8 de septiembre de 2020]. URL disponible en: /news/new-cochrane-review-assesseshow-accurate-antibody-tests-are-detecting-covid- 19

4. Zhang Y, Muscatello D, Tian Y, Chen Y, Li S, Duan W, et al. Role of presymptomatic transmission of COVID-19: evidence from Beijing, China. J Epidemiol Community Health [Internet]. 26 de agosto de 2020 [citado 8 de septiembre de 2020]. URL disponible en: https:// jech.bmj.com/content/early/2020/08/26/jech-2020-2I4635

5. Donis, José $\mathrm{H}$. Evaluación de la validez y confiabilidad de una prueba diagnóstica. Avances en Biomedicina. 20I2;I(2):73-8I. URL disponible en: http://www.redalyc.org/articulo.oa?id=33 | $3280 \mid 5005$

Fecha de recepción: I I-I I-2020.

Fecha de aceptación: 10-01-202I. 